\title{
Residential status of medical students as a factor affecting formative and summative academic performance in Forensic Medicine at Rehman Medical College, Peshawar, Pakistan
}

Submitted

February 10, 2020

Accepted

March 05, 2020

Author Information

Dr. Khalil-Ur-Rehman Associate Professor, Department of Forensic Medicine, Rehman Medical College Peshawar, Khyber Pakhtunkhwa, Pakistan (Corresponding Author) Email:

khalil.rehman@rmi.edu.pk

Dr. Rizwan Faisal

Associate Professor

Department of Pharmacology

Rehman Medical College

Peshawar, Khyber

Pakhtunkhwa, Pakistan

\section{Dr. Rizwan Qaisar}

Department of Basic Medical

Sciences, College of Medicine University of Sharjah

Sharjah, UAE

Dr. Mian Mujahid Shah

Professor \& Head

Department of Forensic

Medicine, Rehman Medical

College, Peshawar, Khyber

Pakhtunkhwa, Pakistan

Citation: Rehman K, Faisal R, Qaiser R, Shah MM.

Residential status of medical students as a factor affecting formative and summative academic performance in Forensic Medicine at Rehman Medical College, Peshawar,

Pakistan. J Rehman Med Inst. 2020 Jan-Mar;6(1):7-10

Dr. Khalil-Ur-Rehman, Dr. Rizwan Faisal, Dr. Rizwan Qaisar, Dr. Mian Mujahid Shah

\begin{abstract}
Introduction: A rigorous characterization of the impact of residential status of medical students (hostelites vs. day scholars) on the particulars of their academic performance has been lacking in Pakistan.
\end{abstract}

Objective: To determine the relation of residential status of third year MBBS students to their academic performance in Forensic Medicine based on comparison of their pre-professional and professional examinations results during 2019

Materials \& Methods: A comparative study was conducted from August to October 2019 on the examination performance of third year MBBS students of Rehman Medical College, Peshawar in the subject of Forensic Medicine. The results of theory and viva preprofessional and professional examinations were compared and categorized by residential status of students (Hostelites or Day Scholars). Students were categorized into groups according to their academic performance. Descriptive and Comparative data analysis was performed by SPSS 22.0, keeping $\mathrm{p} \leq 0.05$ as significant.

Results: No significant difference was found in the mean marks of hostelites and day scholars in preprofessional and professional examinations. The trend of significant improvement from pre-professional to professional examinations was similar in both groups, and it applied to both the theory and viva examinations A significant correlation existed between the performance in two examinations among all students with no difference between the hostelites and day scholars.

Conclusion: Residential status of MBBS students had no effect on their academic performance in the subject of Forensic Medicine.

Keywords: Academic performance, Forensic Medicine, hostelites, day scholars,

The authors declared no conflict of interest. All authors contributed substantially to the planning of research, data collection, data analysis, and write-up of the article, and agreed to be accountable for all aspects of the work.

\section{INTRODUCTION}

Boarding school has been a feature of education systems for centuries. A boarding school provides education for pupils who live on the premises, as opposed to a day school. The word "boarding" is used in the sense of "room and board", i.e., lodging and meals. Now they extend across many countries, their function and ethos vary greatly. Traditionally, pupils stayed at the school for the length of the term; some schools facilitate returning home every weekend, and some welcome day pupils. Some are for either boys or girls while others are co-educational. ${ }^{1}$ The boarding system helped the students in utilization of teachers and was economical as it reduced the need of extra coaching or tuitions. ${ }^{2}$

Both hostelites and day-scholars get their own share of memories from college life. Having their own list of benefits and drawbacks, everyone leaves with a bag full of moments to cherish forever. Strict routine and independence from parents foster self-reliance among boarding school boys and girls. The boarding school environment offers opportunities for personal growth and social development that are unavailable through other means. They have better access to a wide range of activities. Boarding system has also some short comings like meals are not properly managed or cooked. Sometimes roommates and other colleagues are not cooperative enough which may affect the academic performance and social behavior. Some students cannot cope with new environment and have the grief of homesickness. ${ }^{3}$

Lara and Saracostti ${ }^{4}$ stated the importance of parental role in the achievement of a student in the field of education. Hunnum and Park $(2000)^{5}$ reported that the interaction of parents with children is important for the confidence and aspiration of students. It not only keep them motivated but is also a source of relief form anxiety related with routine daily work. ${ }^{5}$ Some researchers believe that day scholars perform much better as residential care and encouragement plays a vital role in improving their academic performance. ${ }^{6}$ According to some other 
researchers, boarding schools were thought to be positively correlated with academic performance as it keeps them away from family and other unnecessary gatherings which are responsible for a significant wastage of time; thus, they can easily study at the hostel without any interference. ${ }^{7}$ Certain studies found no significant difference between the academic performances of the two groups. ${ }^{2}$

The present study was conducted to resolve the conflict of better academic performance among hostelites and day scholars. Outcome of the study may form the basis for paying attention and doing more hard work with the weaker group in order to improve their academic performance. The study may be helpful for college's policymakers to design and implement better policies.

\section{MATERIALS \& METHODS}

This comparative study was carried out at Rehman Medical College, Peshawar, Pakistan, from August to October 2019, and comprised third-year medical students of the sessions 2018-19 by using universal sampling. Confidentiality of all participants was ensured. ${ }^{8,9}$ The course content of Forensic Medicine included law and ethics, forensic aspect of trauma, thanatology, personal identification, toxicology, sexual offences, Forensic psychiatry, and Forensic serology. Same content was included both in pre-professional and professional examination. The pattern of pre-professional examination was kept the same as that of professional examination. Both examinations had two components, i.e., theory and viva voce. Theory paper was further divided into multiple-choice questions and short-essay questions. Record of the result of pre-professional examination was already available in the department while marks of individual students in Forensic Medicine professional examination were obtained from Student Affairs detailed marks certificates. For theory paper, structured key was provided to the examiners in order to eliminate bias when the papers were evaluated. ${ }^{10}$ The list of boarder students was provided by the Student Affairs section and was also confirmed from individual students. Total 98 students were included in the study including 46 hostelites and 52 day scholars. The students were categorized into 5 groups; Group 1:<50\% marks; Group 2: 51-60\% marks, Group 3:61-70\% marks, Group 4:71-80\% marks and Group 5: $>80 \%$ marks. ${ }^{11,12}$

\section{Statistical analysis}

Data were analyzed by SPSS 22.0 for descriptive and comparative analysis. Results are presented using mean and standard deviation as data met the assumption for normality. Analysis of variance (ANOVA) was used to compare groups and Pearson correlation ( $r$ ) was employed to determine the strength of the relationship between residential status and examination performance. Two-sample t-test for proportions was used to compare the exam scores for individual categories based on results. A $p$-value $<0.05$ was considered statistically significant.

\section{RESULTS}

A total of 98 students from 3rd year MBBS of the session 201819 were enrolled in the study. Their ages were from 20-22 years.

No significant differences were found between the hostelites and day scholars in the mean values of theory or practical examinations conducted by Rehman Medical College (Internal Pre-Professional) and Khyber Medical University (Final Professional) (Figure 1).

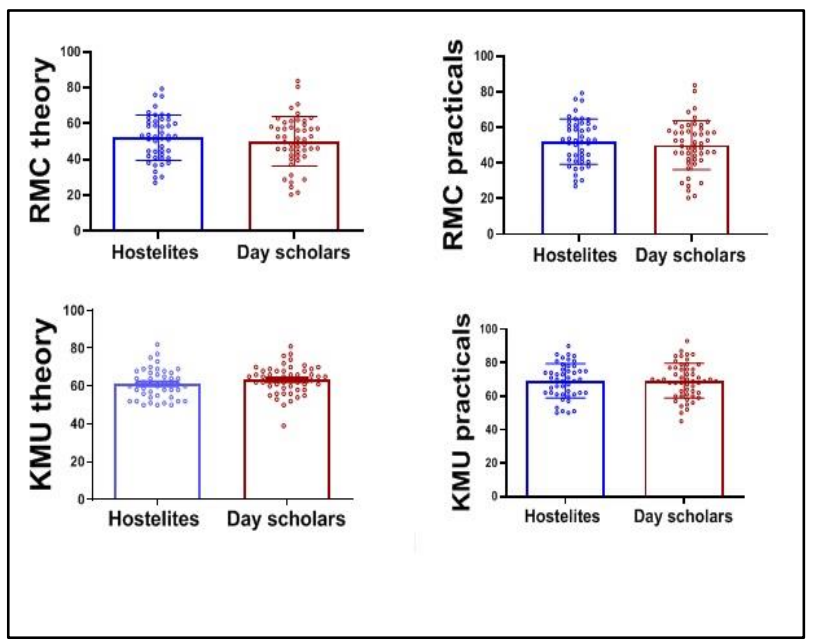

Figure 1: Theory and practical marks of students in internal RMC \& and final KMU examinations, 2019 distributed by Hostelites and Day Scholars. Values are expressed as mean $\pm \mathrm{SD}(\mathrm{N}=46-52$ / group $)$.

Students' performance in pre-professional and professional examinations were compared; in general, students performed significantly better in the professional examinations irrespective of their residential status (hostelites vs. day scholar) or type of exam (theory vs. viva) (all p < 0.05) (Figure 2).

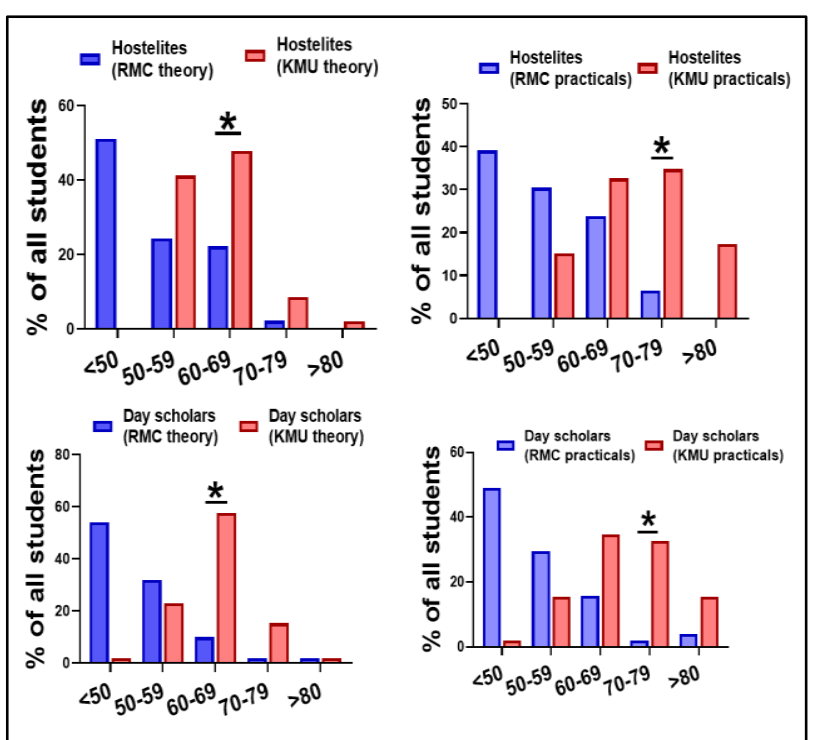

Figure 2: Relative proportions of students based on their theory and practical marks in the internal RMC \& final KMU examinations, 2019, distributed by Hostelites and Day Scholars ( $=46-52$ / group). 
However, the comparisons of mean values do not show the marks distribution of individual students. So we next categorized the marks distributions into five categories ranging from the lowest ( $<50 \%$ marks) to the highest ( $>80 \%$ marks) category with further subdivisions for every $10 \%$ marks between the two categories. Significant differences were found in the category-specific comparisons. For example, for the hostelites, the improvement in the professional exam was statistically significant in the $60-69 \%$ category for the theory exam and $70-79 \%$ category for the viva exam (both $p<0.05$ ) (similar trends were reported in the day scholars (all $\mathrm{p}<0.05$ ) (Figure 3).

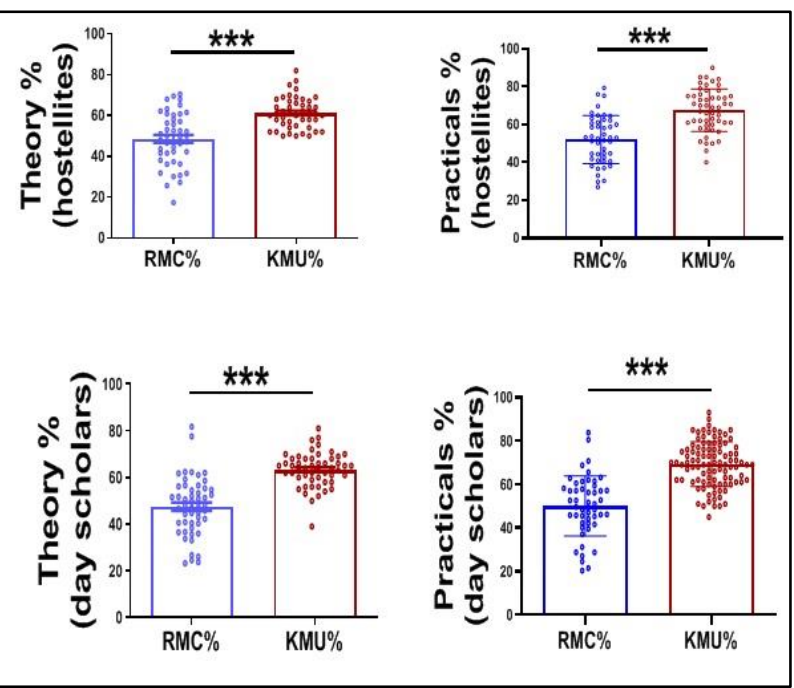

Figure 3: Percentage marks of Hostelites and Day Scholars in RMC and KMU examinations (values are expressed as mean \pm SD $(n=46-52$ / group $)$.

To evaluate if the performance in the pre-professional exam can be a useful predictor of the performance in the professional examinations, multiple regression analysis was done between pre-professional and professional examinations score for the hostelites and day scholars groups. Statistically significant correlation ( $p<0.01)$ was found between the performances of both examinations for both groups of students. However, the strength of correlation was slightly stronger for the hostelites than day scholars $(\mathrm{r} 2=0.66$ vs. 0.56 , respectively). These findings show that the pre-professional score of the hostelites is has more predictive power of their professional score, when compared to day scholars.

A significant difference was also noted when hostelites and day scholars were segregated on the basis of marks' categories in pre-professional examination also revealed significant difference in professional exam (Figure 4).

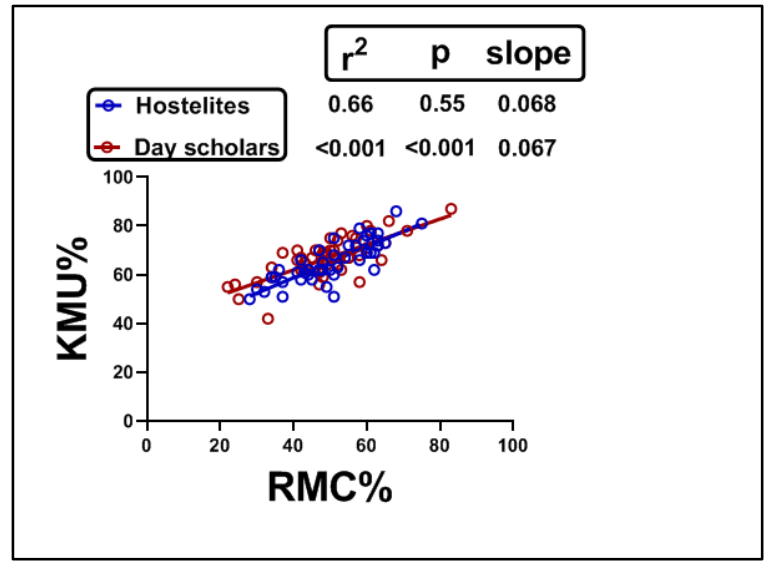

Figure 4: Linear regression analysis between RMC\% and KMU\% marks.

\section{DISCUSSION}

In our study no significant difference was found between the academic performance of hostelites and day scholars both in pre-professional and professional examinations. Academic performance of both hostelites and day scholars was significantly improved in professional examination as compare to pre-professional examination.

Khan et al. conducted a study at Rawalpindi Medical University, Pakistan to compare the academic performance of hostelites and day scholars. Total students included in the study were $287 ; 183$ were hostelites and 104 were day scholars. When they were compared in terms of academic performance, day scholars were found to be better than their other counterparts. ${ }^{13}$ A similar study conducted in India also showed better performance of day scholars academically. ${ }^{14}$

Nayatanga and his colleagues conducted a study to compare the academic performance of hostelites and day scholars. The research covered 248 schools in all the seven districts of the province of Manical and, Zimbabwe. Results of the study revealed better academic performance of the hostelites than day scholars. They concluded that the variations in academic performance were due to improved earning environment boarding. ${ }^{15}$ The hostelites also have ample resources and time for study without the problem of extra household responsibilities at home (Mathematics). Oloo found the same results by performing the same kind of study in Kenya. ${ }^{16}$ The results of our study are in contrast to the above mentioned studies.

Faisal et al performed a study at Rehman Medical College, Peshawar for comparison of academic performance of hostelites and day scholars. Results of 200 students of year 3 MBBS was evaluated but insignificant difference between was found between the two groups. ${ }^{2}$ Similar study was performed at St Matthias Tsonzo High School, between hostelites and day scholars. The results revealed no significant difference between the academic performance of the hostelites and day scholars. They speculated that as the institute motivates and treats both hostelites and day scholars equally, therefore both the groups were found similar in academics. ${ }^{17}$ Our results are in accordance with the findings of these studies. 
Previous studies based on comparison of hostelites and day scholars revealed different results. Results not only vary region wise but also institute wise. Both hostelites and day scholars enjoy certain facilities but also face certain problems. Boarding school may be depressing for some students because of home sickness but it keeps them aside from unnecessary work at home and family gatherings; hence they can easily study without any interference. Day scholars on the other hand are usually thought to have residential care which improves academic performance and relieving stress. But they have to travel a long distance daily to reach their academic institution which is not only time consuming but results in tiredness.

In this modern era with the availability of good academic institutes, better transportation, communication, internet and other resources, both at hostel and home offer almost the same environment for studies. It is also believed by some researchers that it mainly depends upon the students themselves; they think it to be a pure individual effort that counts. Keeping in view all these facts, residence will have little or no effects on academics. Same are the findings in our study, insignificant difference between the academic performance of the hostelites and day scholars are found in both the examinations, though the marks were improved by almost all the students in the professional exam which is more likely due to the availability of preparatory leaves and their more focused behavior towards studies.

\section{CONCLUSION}

Results of the study revealed improvement in the marks of professional examination as compare to pre-professional examination both by hostelites and day scholars. However, we found no significant difference between the academic performance of the hostelites and day scholars.

\section{REFERENCES}

1. Martin AJ, Papworth B, Ginns P, Liem GAD. Boarding school, academic motivation and engagement, and psychological well-being: A large-scale investigation. American Educational Research Journal. 2014;51(5):1007-49.

2. Faisal R, Shinwari L, Izzat S. Academic performance of day scholars versus boarders in pharmacology examinations of a medical school in Pakistan. J Pak Med Assoc. 2016;66(9):1094-97.

3. Bahadar N, Mahnaz W, Jadoon S, Jadoon $\mathrm{S}$. A comparative analysis of the behaviors and performance of day scholar and boarder students at secondary school level. American Journal of Educational Research. 2014;2(8):600-2.

4. Lara L, Saracostti M. Effect of parental involvement on children's academic achievement in Chile. Frontiers in psychology. 2019;10:1464.

5. Đurišić M, Bunijevac M. Parental involvement as a important factor for successful education. Center for Educational Policy Studies Journal. 2017;7(3):137-53.

6. Little M, Kohm A, Thompson R. The impact of residential placement on child development: Research and policy implications. International Journal of Social Welfare. 2005;14(3):200-9.
7. Perveen S, Kazmi SF. Personality dynamics of boarders and day scholars who belong to madrassah and public school. Academic Research International. 2011;1(1):157-72.

8. Faisal $\mathrm{R}$, Shinwari $\mathrm{L}$, Mateen $\mathrm{H}$. Evaluation of the academic achievement of rural versus urban undergraduate medical students in pharmacology examinations. Asian Pacific Journal of Reproduction. 2016;5(4):317-20.

9. Faisal R, Popalzai AJ, Sultana U. Class attendance of pharmacology students of Rehman Medical College as a determinant of academic performance. J Rehman Med Inst. 2017 JulDec;3(3-4):11-5.

10. Faisal R, Laiyla S. Comparative assessment of students' academic performance in multiple choice questions versus short essay questions in pharmacology examinations of a medical college of Pakistan. J Rehman Med Inst. 2015 Jul-Dec;1(2):23-8.

11. Faisal R, Shinwari L, Hussain SS. Academic performance of male in comparison with female undergraduate medical students in Pharmacology examinations. J Pak Med Assoc. 2017 Jan;67(2):204-8.

12. ur Rehman K, Shah MM, Faisal R, Khan MSG. Academic performance of undergraduate medical students with and without preparatory leaves in the examinations of basic sciences. Journal of Medical Sciences. 2017;25(2):205-8

13. Khan MS, Malik AR, Butt AUA, Khalid A, Maqbool S, Khan H, et al. Personality Dynamism and Academic Performance Among Boarders and Non-boarders Studying in a Medical University. Cureus. 2019;11(7).

14. Aruna T, Srirupa H, Vangaveti $S$. Assessing altered sleep patterns among medical students. J Pharm Sci Innov. 2015;4:59-64

15. Nyatanga EK, Ndudzo D. Disparities in performance in mathematics between boarding and non boarding schools: a study of the seven districts of Manicaland province, Zimbabwe. IOSR-JBM. 2015 May;17(5):1-5.

16. Oloo MA. Gender disparity in students' performance in KCSE in mixed day secondary schools in Migori district Kenya. (Masters' thesis): Maseno, Kenya: Maseno University; 2003.

17. Mandiyamba G. An investigation into the disparities in performance in $\mathrm{O}$ level mathematics between boarding school pupils and day school pupils at St Matthias Tsonzo High (Doctoral Dissertation) Bindura, Zimbabwe: Bindura University of Science Education; 2016. 